\title{
DESIGN DE INTERFACES PARA EXPERIÊNCIAS LÚDICAS COM NOVAS TECNOLOGIAS: O CASO DO SOFTWARE-LIVRE REACTIVISION EM INTERAÇÕES SONORAS
}

\author{
Elen Nas \\ PUC-Rio \\ sereialab@gmail.com \\ Jorge Lopes \\ PUC-Rio \\ jorgelopes.int@gmail.com
}

Resumo: Projetar experiências lúdicas ultrapassam as fronteiras entre Arte e Design. O Design de Interface com novas tecnologias deve ser pensado do mesmo modo que o Design de Produto, pois, em seu aspecto filosófico, a interação-humano-computador deve ser entendida como uma interação humano-humano. Desse modo, trabalhos artísticos que envolvem Design de Interação podem nos inspirar a olhar estas relações por outros ângulos. Este artigo mostra algumas experiências com o software Reactivision, desenvolvido na Universidade Pompeu Fabra para o instrumento eletrônico Reactable.

Palavras-chave: Design de Interface, Design de Experiência, Design Sonoro.

Abstract: Design for ludic experiences goes beyond the borders between Art and Design. The Interface Design for new technologies must be thought as the same as Product Design because, in their philosophical aspects, the human-computer interaction has to be understood as human-to-human interaction. On that sense, artistic works that combines Interaction Design can inspire us to look those relations from different aspects and views. This paper shows some experiences with Reactivision software developed at Pompeu Fabra University for the product Reactable.

Keywords: Interface Design, Experience Design, Sound Design. 


\section{INTRODUÇÃO}

We need to understand and design for interaction in a world where the notion of an interface is no longer easily defined, stable or fixed. (HARPER, 2009)

Hoje vivemos em um ambiente de crescente ubiquidade computacional e devemos nos perguntar como interagimos com todos os dispositivos que estão a nossa volta. Se considerarmos o conceito de calm technology (WEISER, 1991) podemos constatar que, ainda que invisíveis, todos estes dispositivos criados pelas possibilidades proporcionados por maiores conhecimentos nas áreas da Tecnologia, Comunicação e do Design vêm a requerer mais intimidade do usuário, não apenas com as interfaces físicas, como também com os pensamentos que as geraram.

$\mathrm{O}$ trabalho aqui apresentado defende, no campo conceitual, a necessidade em se criarem experiências lúdicas, artísticas, criativas, dentro das relações entre arte, ciência e tecnologia, como forma de aproximar as pessoas em geral de um debate sobre as nossas relações com as tecnologias, as máquinas, os ambientes artificiais e os fenômenos científicos. $E$, quando não acontece exatamente um debate, a defesa é para que haja um número maior e crescente de experiências que agreguem novas memórias e percepções neste campo.

Neste artigo cita-se o pensador Vilém Flusser e o historiador da arte Andreas Broeckman, entre os trabalhos que visam compreender a interação humanocomputador do ponto de vista da Arte e do Design, e resultados de experiências científicas utilizando tecnologias similares ou idênticas aos dos experimentos aqui relatados.

\section{DESENVOLVIMENTO}

A sociedade contemporânea demanda diálogos com as novas tecnologias e, por este motivo, muitos artistas e designers exploram este campo de maneira consciente buscando diálogos dentro do que seria "a tensão da luta entre o humano e máquina num sistema aberto e instável"(BROECKMANN, 2009).
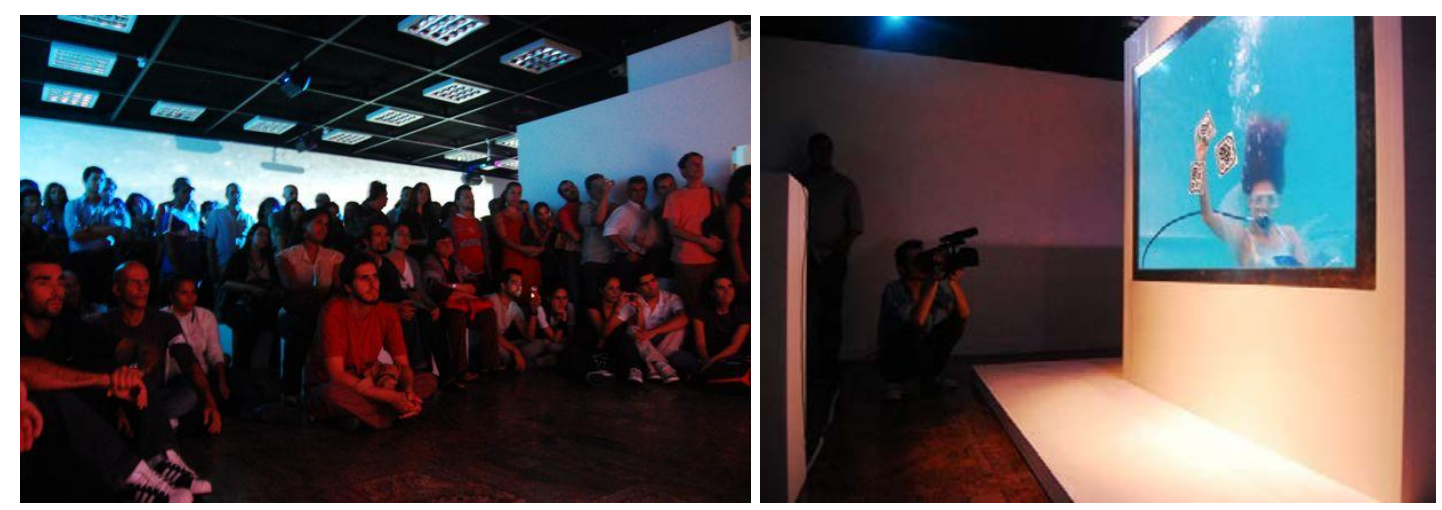

Fig. 1 e 2: Abertura da Exposição Sereia Lab: Instalação Sonora em Escamas Sensoriais, Rio de Janeiro, 2009.

Inicialmente a escolha dos softwares veio de uma solução para o primeiro trabalho realizado, apresentado como exposição sensorial e interativa. 
Embora fora das preocupações do campo acadêmico, o trabalho envolvia a necessidade da experiência do público com novos recursos disponíveis e acessíveis em rede.

ReacTIVision foi de grande importância nesta experiência, e é um Software Livre que permite sua adaptação em diferentes contextos. Ele foi criado inicialmente para fazer parte do sistema Reactable, um instrumento que ficou conhecido em 2007 através da cantora islandesa Bjork.

A solução que o software proporcionou foi, através do seu sistema de reconhecimento ótico, fazer com que a performer pudesse tocar sua programação sonora de dentro d'água.
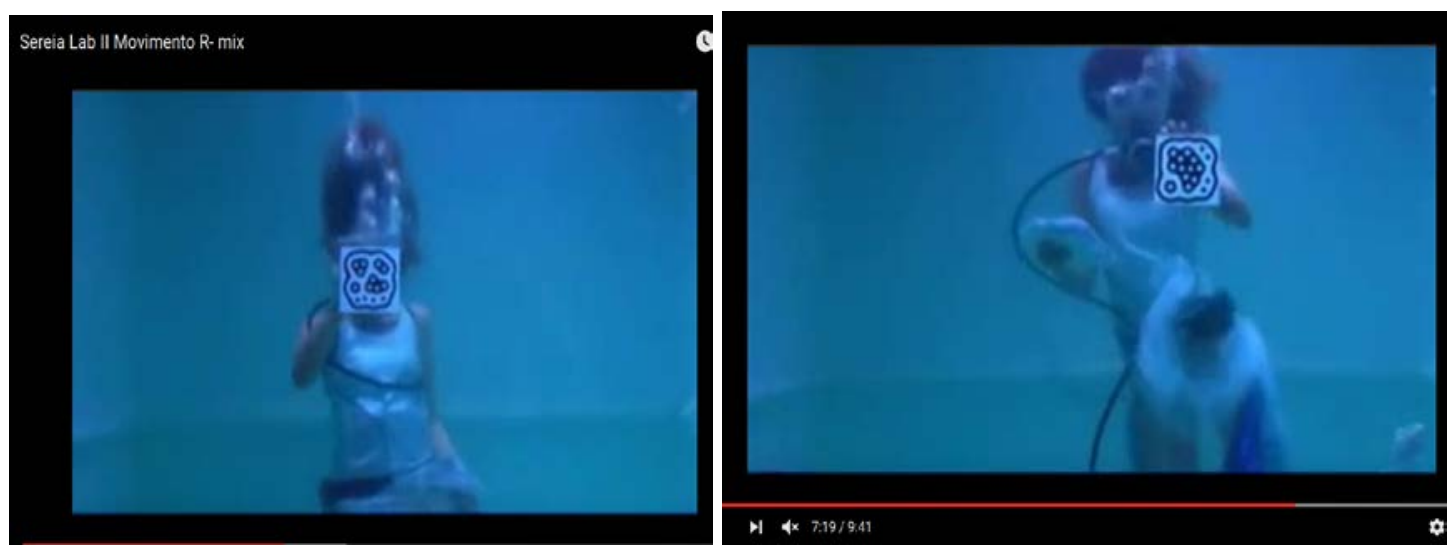

Fig. 3 e 4: Performance Sereia Lab, Rio de Janeiro, 2009.

A experiência do público, além de vivenciar as performances ocorridas durante o período de exposição, foi também manusear as imagens capazes de acessar uma biblioteca sonora, assim como vivenciar outros recursos sensoriais preparados no ambiente da exposição.

No decorrer do período da exposição houveram descobertas: tanto a performer buscava encontrar maneiras de entender aqueles desenhos, dar-lhes nomes e formas para aprimorar sua comunicação com o ambiente externo, enquanto estava debaixo d' água, como também em momentos em que o público experimentava acessar os sons com os desenhos, fatos inusitados como o de estudantes copiarem os desenhos a lápis, fazendo-os tocar da mesma maneira, ocorreram!

A partir daí a artista passou a pesquisar o quão flexíveis poderiam ser estes desenhos, lhes deu novas formas e imagens. A relevância de tal feito foi que, além de materializar elementos da imaginação que passaram a ocorrer apenas durante a experiência na performance debaixo d' água, a artista foi também a primeira pessoa que, ao tomar contato com as possibilidades do Reactivision, resolveu criar suas próprias imagens com objetivo de criar narrativas e dar-lhes uma personalidade distinta dos desenhos padrão gerados computacionalmente.

A estes desenhos deu-se o nome de Pictogramas Sonoros Interativos e uma sequência de experimentos independentes de compromissos profissionais ou acadêmicos se iniciaram. 


\subsection{Experimentos Intermediários}

\subsubsection{Cubos Sonoros}
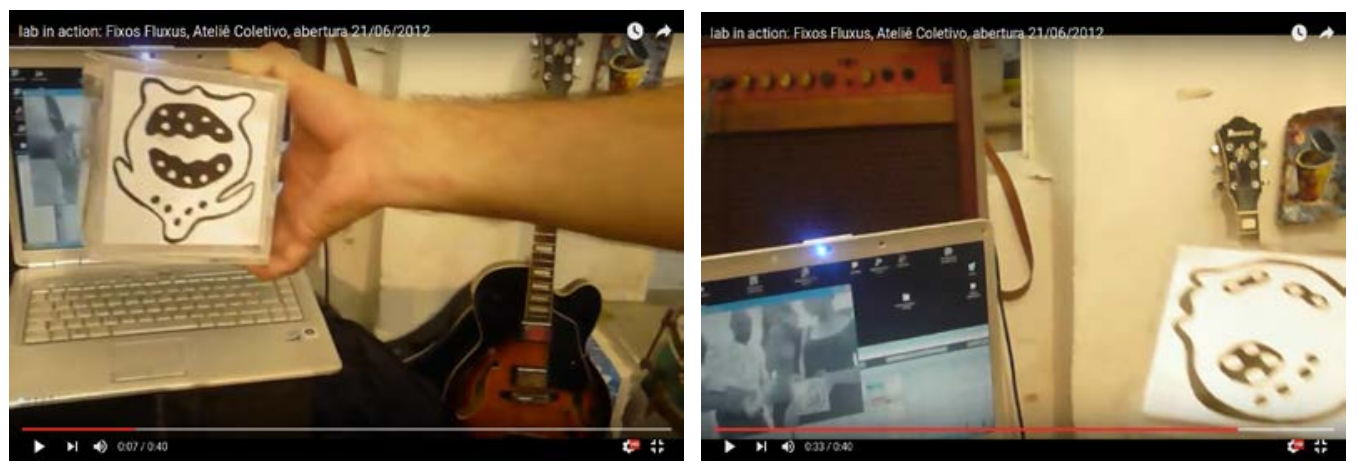

Fig. 5 e 6: Primeiro experimento público com os Pictogramas Sonoros Interativos na Coletiva de Artistas "Fixos Fluxos", Lapa, RJ, 2011.

Dentro de um ambiente descontraído, um ateliê coletivo aberto ao público, o Design de Som escolhido para ser acessado pelas imagens desenhadas a mão e reconhecidas pelo Reactivision, foi uma sequência de sons que se multiplicam a partir de uma frequência fundamental. Desta maneira as pessoas puderam manusear os cubos em frente a câmera do computador e lançar sons para o ambiente.

\subsubsection{Roupas e Cubos para efeitos sonoros}

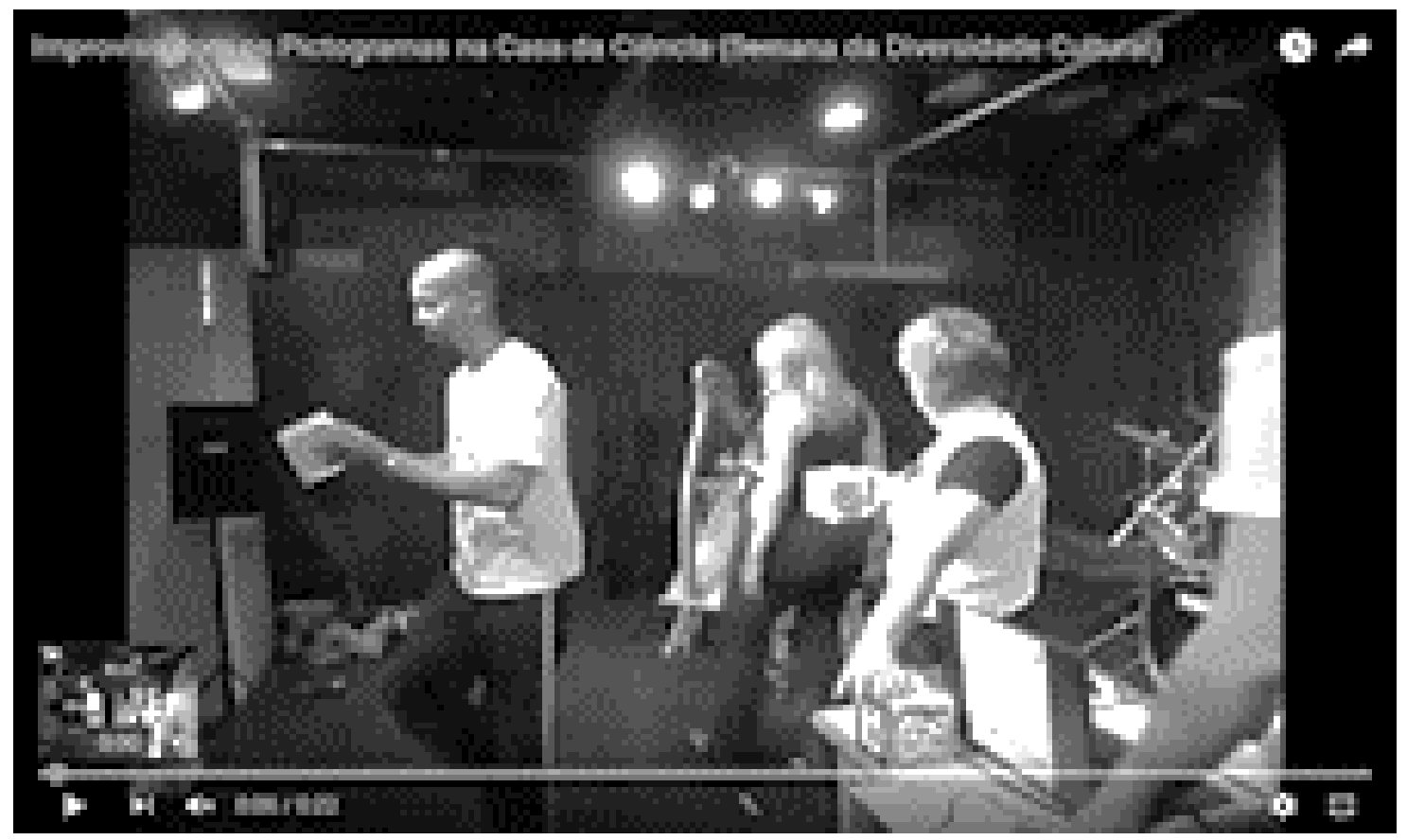

Fig. 7 e 8: Segundo experimento público com os Pictogramas Sonoros Interativos na Semana da Diversidade, UFRJ, 2012.

Um encontro inusitado promovido pela UFRJ proporcionou a integração de pacientes psiquiátricos através de oficinas, concertos e outras atividades culturais. 0 experimento foi levado ao palco para que, juntamente com uma harpista, os desenhos pudessem acessar a bateria contínua do Bolero de Ravel, assim como agregar a 
performance musical elementos de sonoplastia como pássaros cantando, sons de cachoeira, ondas do mar, etc. Três pessoas se voluntariaram para vestir camisas com os desenhos dos Pictogramas (que foram utilizadas e testadas pela primeira vez).

\subsubsection{Adesivos sonoros}

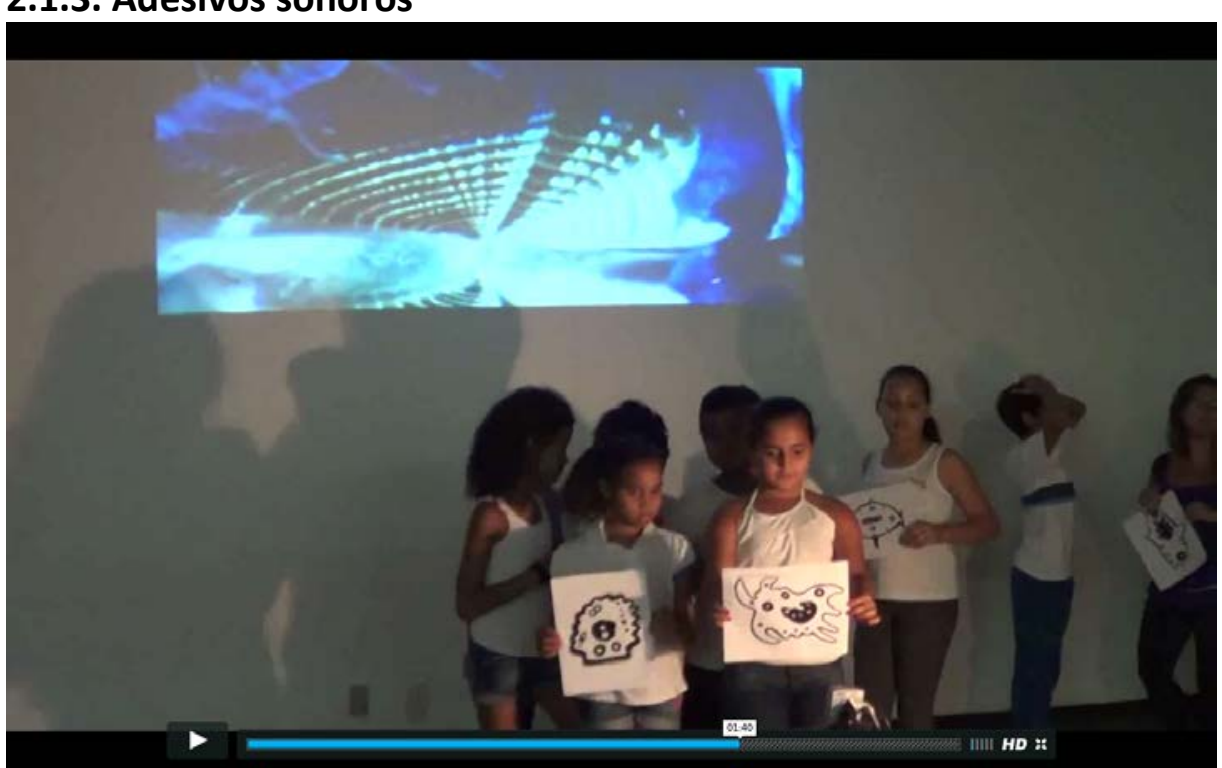

Fig. 9: Terceiro experimento público com os Pictogramas Sonoros Interativos na Casa da Ciência, Rio de Janeiro, 2012, dentro do Programa Educativo "Clube dos Descobridores".

A Casa da Ciência, através do Programa que realizava diariamente com estudantes de Escolas Públicas do Município do Rio, atividades de aprendizado científico, recebeu o projeto dos Pictogramas Sonoros Interativos ainda em fase embrionária. Foram preparados adesivos das imagens para serem colados as camisetas e uma canção folclórica, cantada por crianças, foi escolhida, para criar uma brincadeira de juntar as partes da canção desmembrada em trechos através da organização das imagens.

\subsubsection{Estúdio de Som e Máscaras Sonoras Interativas}

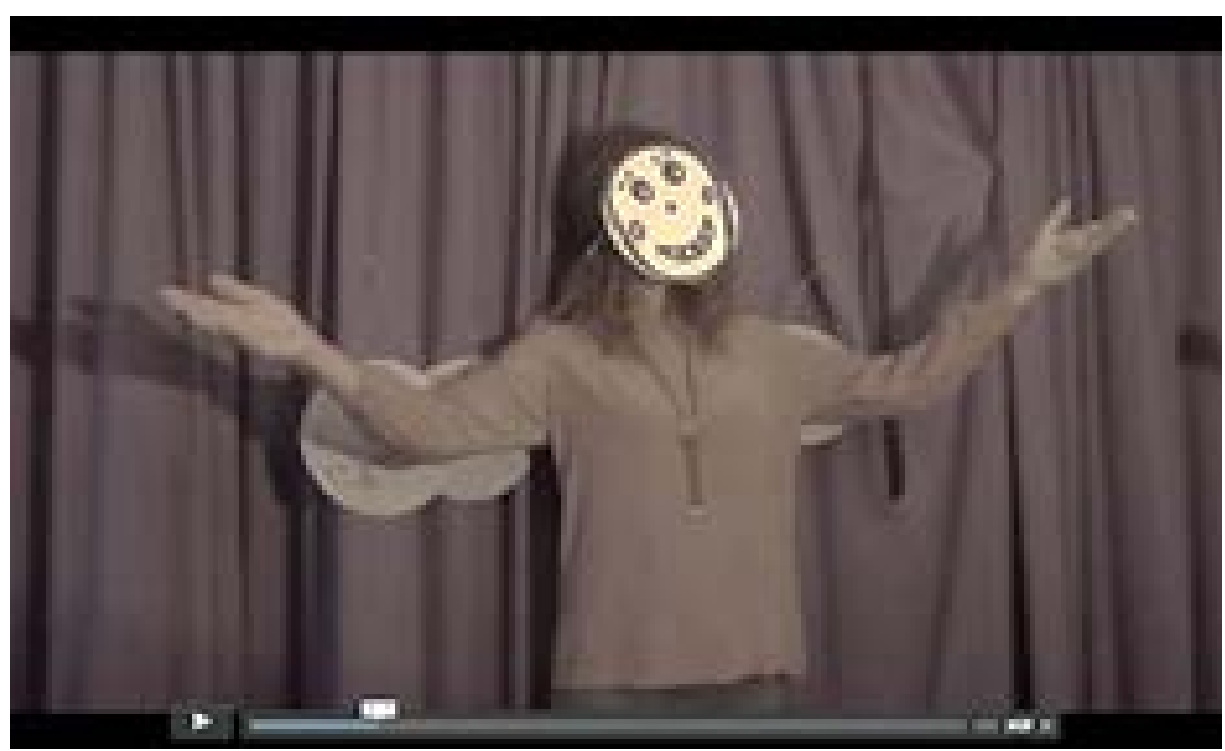

Fig. 10: Mememi Estúdio de Oratória no Congresso Scientiarum Historia, UFRJ, 2012. 
Dentro do Congresso da Pós-Graduação em História da Ciência, Técnicas e Epistemologia, foi montado um Estúdio Aberto onde os congressistas podiam se expressar verbalmente. Seus depoimentos, declamações e improvisos eram gravados e em seguida podiam ser acessados pelas máscaras presas a uma cortina. A tela do computador projetada na parede auxiliava no monitoramento das leituras óticas e gravações.

\subsubsection{Vestíveis para Performance e Pinturas para Trilha Sonora.}

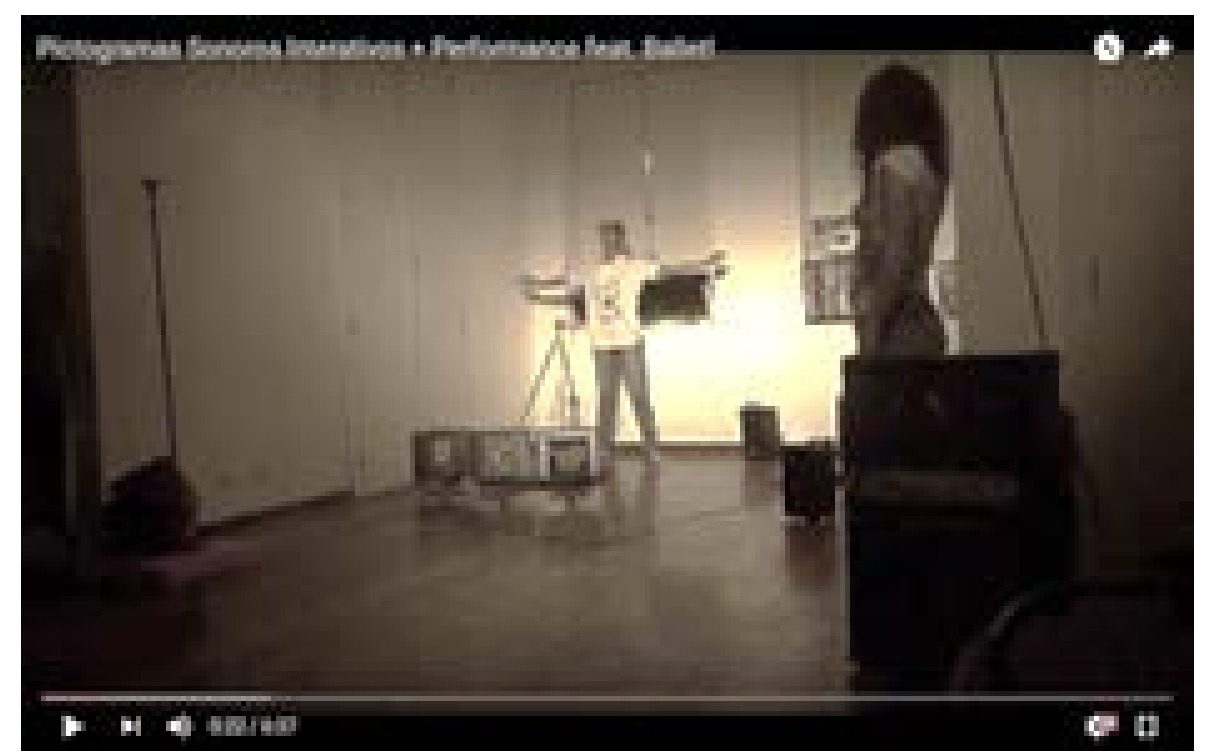

Fig. 11: Casa Ser Cidadão, Santa Cruz/RJ, 2013. Mostra de Artes Integradas.

Atendendo ao convite da Casa Ser Cidadão na Zona Oeste do Rio, o objetivo era criar uma trilha sonora para que um jovem bailarino premiado, morador da região, pudesse realizar uma breve performance. $O$ bailarino não somente aceitou fazer um improviso com "música concreta" e vestir camisas e máscaras para acessar alguns sons, como também se mostrou muito fascinado com a oportunidade de ter feito tal experimento, que levou na bagagem para a Escola de Ballet em Miami, para a qual foi selecionado com Bolsa de Estudos. Nesta experiência, outros sons foram agregados através de pinturas em telas e papéis dispostas no fundo do plano.
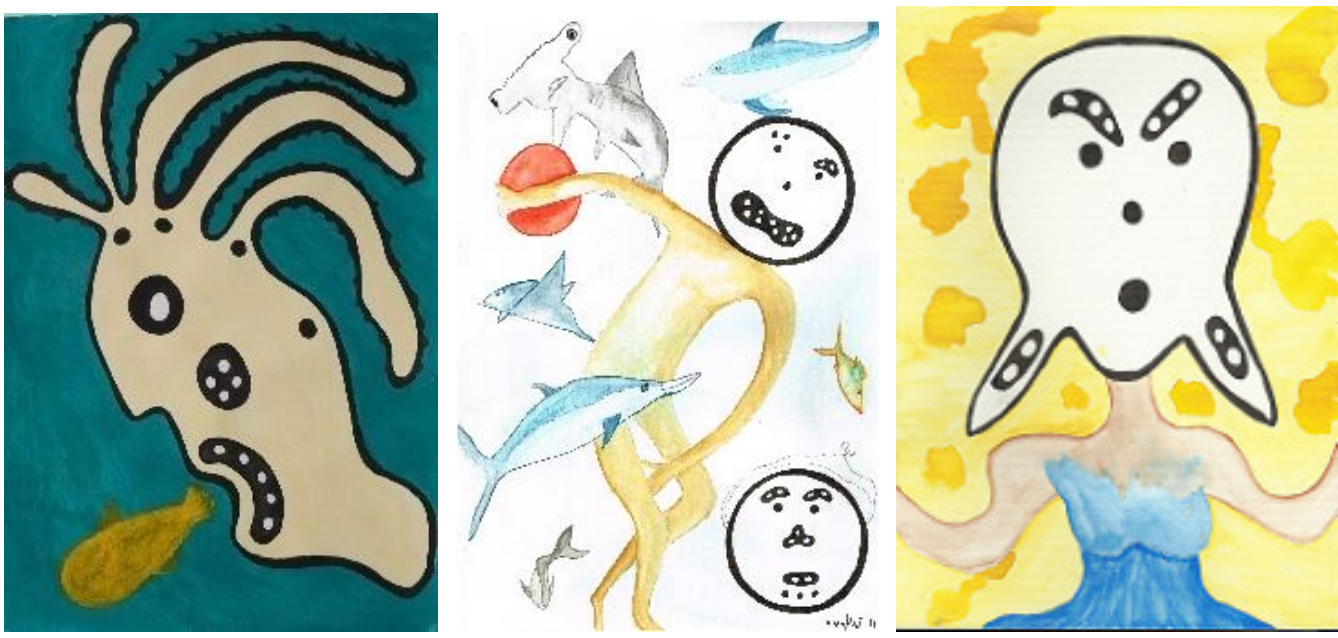

Figuras 12, 13 e 14: Pinturas com os Pictogramas Sonoros Interativos, 2011-2014. 


\subsection{Experimentos na PUC-Rio (LIFE- Laboratório de Interfaces Físicas Experimentais)}

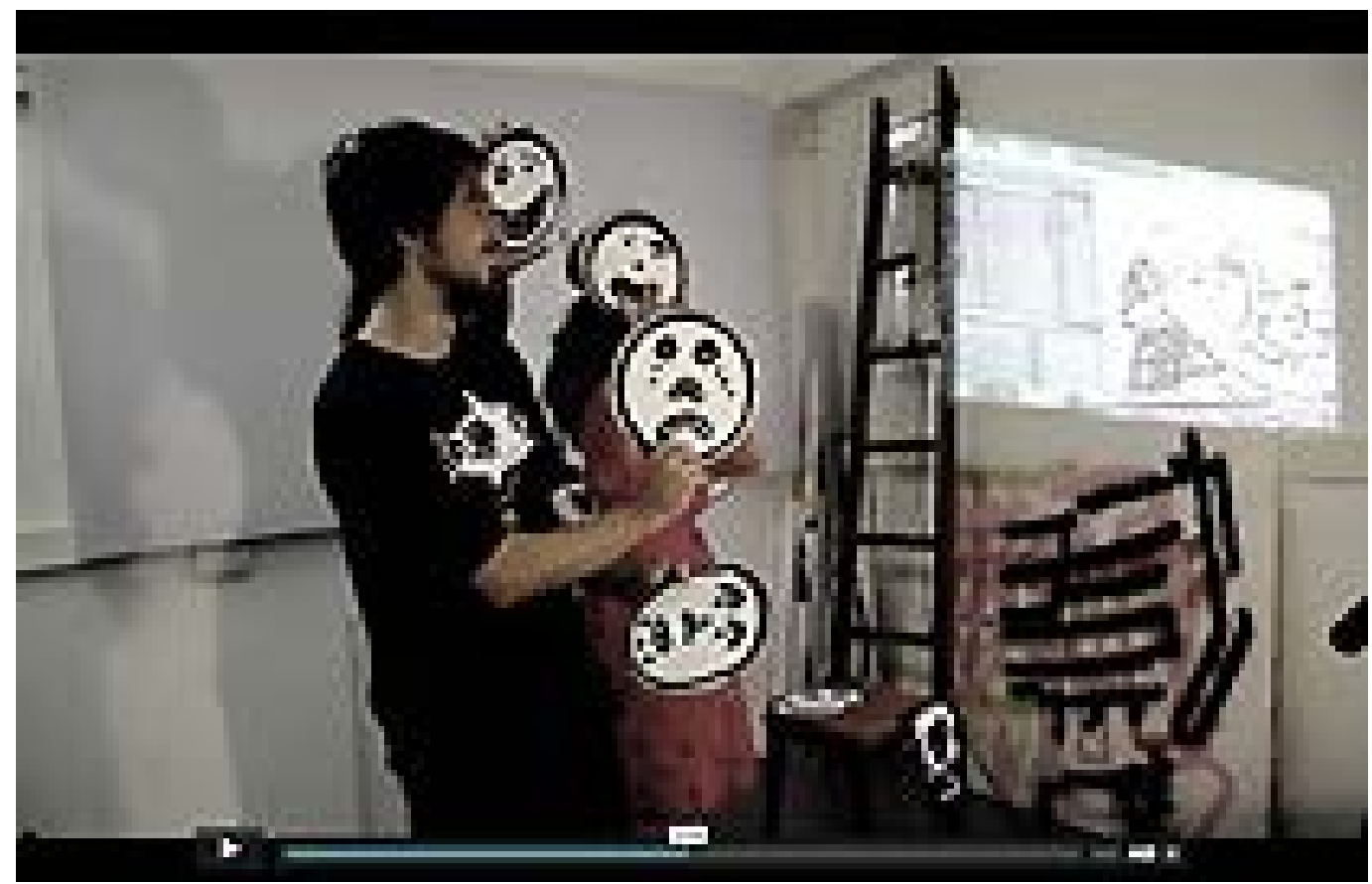

Fig. 15: Laboratório de Interfaces Físicas Experimentais, PUC-Rio, 2015.

Enquanto os "Experimentos Intermediários" foram feitos como pesquisa independente, apenas focados em testes e desenvolvimento, sem necessidade de colher impressões das experiências das pessoas e de produzir relatórios de pesquisa, o objetivo de fazer novos experimentos com os Pictogramas Sonoros Interativos dentro de um compromisso acadêmico com o Programa de Pós-Graduação em Design da PUCRio foi de sistematizar os conhecimentos e experiências adquiridas em campo para uma análise mais aprofundada das questões que envolvem realizar tais trabalhos, em contato direto com todos os tipos de público, refletir sobre métodos de pesquisa e as contribuições que trabalhos que conjugam arte, ciência, tecnologia de maneira ampla e sem definições restritas possam vir a agregar para desenvolvimento de vidas e saberes.

\subsubsection{Novos Pictos}

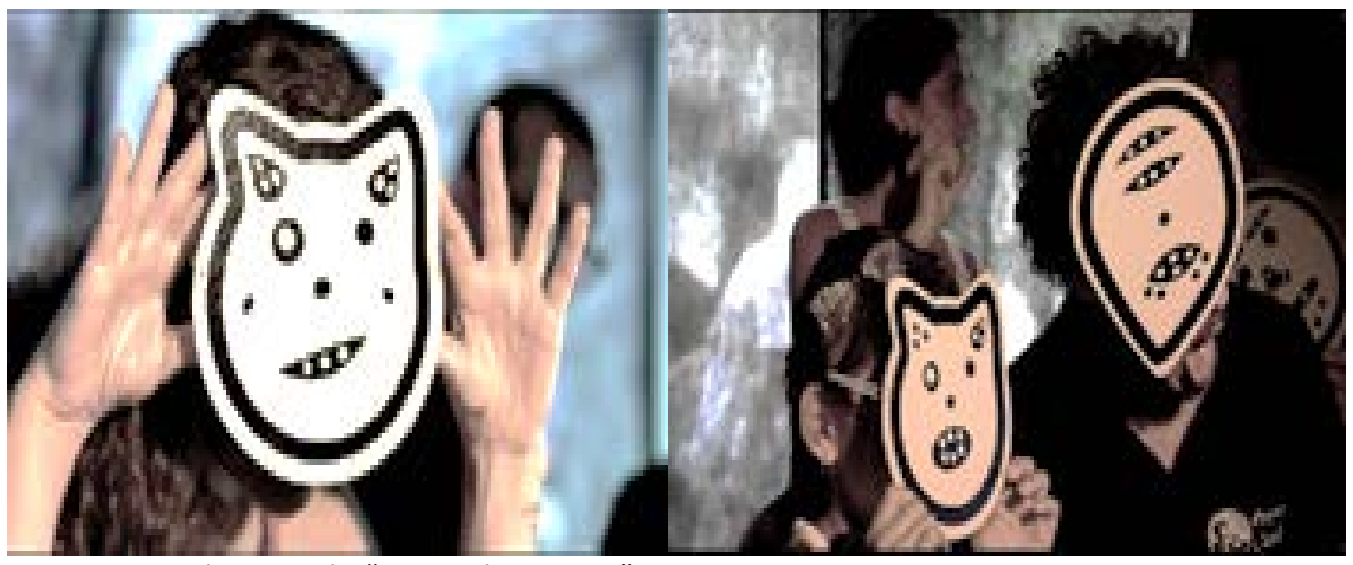

Fig. 16 e 17: Abertura do "Rio Hacker Space", Santa Teresa, 2015. 
Com o objetivo de ampliar o vocabulário dos Pictogramas Sonoros Interativos foram produzidos em série os "Novos Pictos" que diferem dos pioneiros desenhados e pintados a mão, por terem sido produzidos digitalmente com auxílio de softwares para facilitar o desenho rápido e cortes por máquinas. Eles foram atração no Rio Hacker Space que abriu as portas do laboratório de garagem para toda comunidade.

\subsection{Análise das Experiências}

Primeiramente foi constatado que as relações das pessoas com experimentos envolvendo Reactivision foram similares aos relatados nos artigos aqui citados como referência, organizados pelos pesquisadores do Grupo de Tecnologia Musical da Universidade Pompeu Fabra, e também apresentados na Conferência Internacional Novas Interfaces para Expressão Musical (NIME).

Eles trabalharam com experiências mais complexas, onde havia uma colaboração na composição do som em tempo real e os usuários buscavam consciência sobre os mapeamentos sonoros para um design de som expressivo.

Nos nossos experimentos o som também era acessado em tempo real, os usuários buscavam também entender mais do processo para obter um maior controle e consciência do que estavam fazendo, embora o mapeamento sonoro era bem mais simples.

Nos artigos enviados ao NIME os pesquisadores narram os comportamentos dos participantes de acordo com seus perfis, separados por idade, sexo, experiência de ter (ou não) de formação / musical. No caso das composições feitas de forma colaborativa, foram formados grupos mistos, o que tornou a avaliação mais complexa (Xambo, et ai, 2014).

Os resultados similares que encontramos foi a necessidade de entender o funcionamento, assim como a de identificar o som de acordo com as imagens, de modo a poder interferir de forma mais ativa sobre os resultados da experiência sonora

\subsubsection{Questionário}

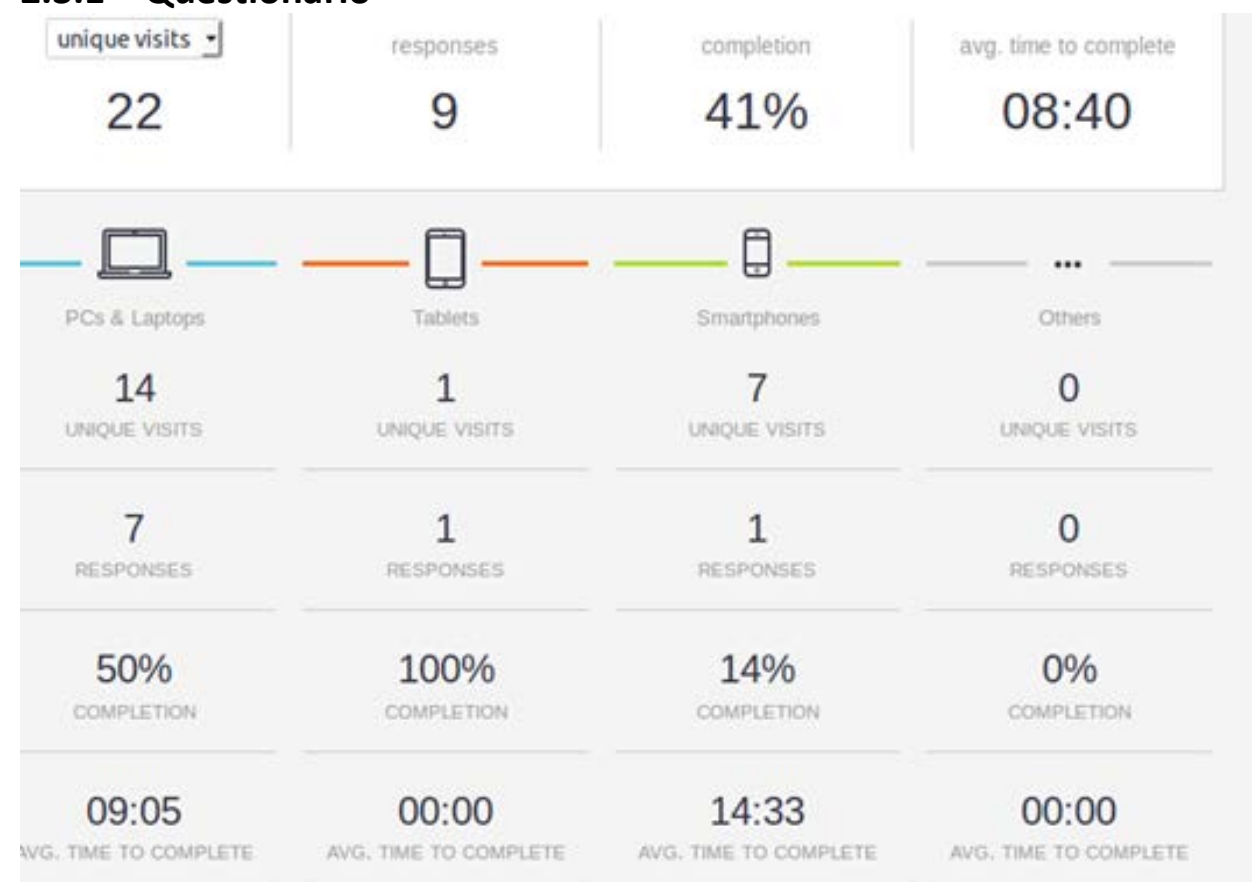

Figura 18: Imagem de tela do questionário. Respostas coletadas a partir de abril de 2015. 
Algumas pessoas que tomaram contato com o experimento foram convidadas a responder o questionário que chegou através dos seus emails. Menos da metade se dispôs a responder, a maioria utilizando computadores/desktops, gastaram menos de 10 minutos e menos da metade respondeu todo o questionário de apenas 6 perguntas.

Todos estudantes de graduação e pós-graduação nas áreas de Design e Música, consideraram a interface de fácil entendimento e a experiência satisfatória.

\subsubsection{Diálogo inter-subjetivo}

O diálogo intersubjetivo é a potência presente nas idéias materializadas em objetos e situações projetadas pelo Design, característica apontada por Flusser (2007) ao refletir sobre a carga de informações e intenções presentes nos projetos. O questionário enviado e respondido poucas ou muitas horas depois da experiência com os Pictogramas Sonoros Interativos procurou abrir esta possibilidade de diálogo que por um lado incita reflexão, e recebe de volta novas reflexões. Assim, metade das perguntas dava possibilidade de incluir comentários:

\section{Questão 1: "A experiência te trouxe algum novo insight, ou te fez refletir sobre algo?"}

Respostas:

(Pessoa 1) "Sim. Sobre a possibilidade de usar palavras como sons.";

(Pessoa 2) "Sim. Me fez ficar "dançando" durante e ficar "ritmado" pela música mesmo depois do experimento. O que refleti foi sobre o nível de controle e delay do experimento.";

(Pessoa 3) "Sim, me fez pensar em várias maneiras de utilizar esse mecanismo que está sendo desenvolvido em música experimental, em grupos, visando a criatividade e a interação (como orfanatos ou casas para idosos), entre outras coisas. Cheguei até a sonhar com o experimento!";

(Pessoa 4) "A experiência me fez pensar na interação de imagem e som. Ao realizar a experiência, fiquei mais preocupado com o resultado sonoro, em pegar os desenhos e entender qual era a interferência que gerava no som, e quando percebia, tentava acompanhar o ritmo, ou interferir acrescentando uma interferência";

(Pessoa 5) "Pessoalmente, gostei bastante da música gerada... Apesar de haver uma desordem, há também um padrão que no final agrada aos ouvidos e que instiga a tentar outros sons e novos movimentos. Fora isso, serviu de inspiração para a execução de um projeto que estou trabalhando atualmente.";

(Pessoa 6) "Não vi o resultado do experimento, mas achei divertido e gostei de poder ajudar na pesquisa de alguém." 
Questão 2: "Você experimentou alguma expectativa ou ansiedade, para procurar desvendar, entender, ou explicar para si mesmo, como se dá o funcionamento técnico deste trabalho?"

Respostas:

(P1) "Sim, ficava tentando entender o tempo de resposta e como ocorria a mudança."; "Sim, mas ainda assim gostei da experiência.";

(P2) "Sim, fiquei com receio de não compreender o funcionamento, mas depois de explicado pareceu simples.";

(P3) "Sim, o experimento gera uma curiosidade no participante ao ouvir sons relacionados com as diferentes imagens que ele usa. Foi difícil entender quais imagens geram qual som quando tem mais de uma pessoa utilizando, mas com apenas uma pessoa e um pictograma fica mais fácil de descobrir. No decorrer do experimento, é legal olhar para a imagem para ver como o computador interpreta, a imagem que ele gera, e o software de som trabalhando por trás. Mas a programação não é clara, pois não aparece na tela, o que deixa o experimento ainda mais misterioso se somado aos sons provocantes, disparados pelas máscaras";

(P4) "Sim. Isso ocorreu pelo fato de nem sempre o padrão ser identificado pela câmera... Algumas vezes eu me perguntava: "eu que não estou entendendo a lógica ou o computador que não está identificando o desenho?" Porém, o trabalho em si tem um funcionamento muito intuitivo.";

(P5) "Sim, a princípio fiquei curioso para saber do que se tratava o sistema de filmagem em preto e branco."

\section{Questão 3: "Acredita que tais dúvidas e questões tenham interferido na possibilidade de uma maior interação com o trabalho?"}

Respostas:

(P1) "Na verdade aumentaram a interação, fiquei mais tempo para tentar descobrir mais sobre.";

(P2) "Sim, pois em alguns momentos não conseguia entender o que as máscaras estavam acionando, a falta de clareza dificultou um pouco a interação.";

(P3) "Não, o trabalho acontece de qualquer forma, pois quanto mais você não entende, mais você quer experimentar para ver o que acontece."

\section{CONCLUSÃO}

Como conclusão preliminar entendemos que o desafio diz respeito a adaptar-se a novas formas de linguagem e de estarmos abertos e dispostos a iniciar novos aprendizados cognitivos.

O que a maioria dos usuários investigados, incluindo os testes feitos no LIFE da PUC-Rio, em três datas diferentes, demonstraram foi que a necessidade de entendimento poderia ser facilmente abandonada se a experiência sonora trazia 
memórias agradáveis, com sons que causavam divertimento, estimulavam dançar e comunicar com os outros.

Desse modo, os experimentos migravam rapidamente de sua característica obstrutiva (FLUSSER, 2007), seja pela complexidade, seja pela limitação de quem o criou, para o seu oposto desobstrutivo, promotor de comunicação fluída.

A ambiguidade do Design problematizada por autores como Flusser entra em foco para transparecer que antes de projetos e conceitos, são idéias e crenças que estão mediando as relações humanas, e não apenas objetos e planos. Assim, a remoção de obstáculos acontece tanto através de produtos de difícil assimilação, quanto por aqueles que se apresentam completamente adaptáveis.

Os desafios projetuais expressos em artefatos, obras artísticas e as diversas produções que consideram o intangível dizem respeito a cultura onde estão inseridos. Estar consciente da cultura, como lembra Flusser, é o desafio do Design.

\section{REFERÊNCIAS}

BROECKMANN, Andreas. Imagem, processo, performance, máquina: aspectos de uma estética do maquínico. Arte, ciência e tecnologia: passado, presente e desafios. São Paulo: Fundação Editora da Unesp, 2009.

FLUSSER, Vilém; CARDOSO, Rafael; ABI-SÂMARA, Raquel. O mundo codificado: por uma filosofia do design e da comunicação. Editora Cosac Naify, 2007.

JORDÀ, Sergi; MEALLA, Sebastián. A methodological framework for teaching,evaluating and informing NIME design with a focus on expressiveness and mapping. In: NIME. 2014. p. 233-238.

NOVAES, Luiza. The Reflective Practice in Interaction Design at PUC-Rio's Design Program. International Journal of Education and Research 1 (12).

HARPER, R. et al. Being Human-Human-Computer Interaction in the year 2020. Microsoft Research. Retrieved November 22, 2009. 2.

WEISER, Mark. The computer for the 21st century. Scientific american, v. 265, n. 3, p. 94-104, 1991.

XAMBÓ, Anna et al. SoundXY4: supporting tabletop collaboration and awareness with ambisonics spatialisation. 2014. 